\title{
Damage assessment of infrastructure based on urban flood inundation simulation
}

\author{
Zhu Yifan ${ }^{1}$, Yu Ping ${ }^{1}$, and Wang Peng ${ }^{1, *}$ \\ ${ }^{1}$ Faculty of Civil Engineering and Mechanics, Jiangsu Unicersity, Jiangsu, China
}

\begin{abstract}
Flood is a serious challenge that increasingly produce immense economical and ecological damages in worldwide. Flood simulation is gradually becoming a central focus of the hydrology in recent years. It is worthwhile to combine flood simulation with flood damage to infrastructure. The purpose of this study is to develop an approach for better urabn flood simulation at different return periods and assess the damage of flood to infrastructures in different return period. The approach is organized into four parts: design rainstorm event simulation, runoff simulation, flood inundation simulation and submerged infrastructures extraction. Base on the flood simulation, we draw the flood inundation map of XuanwuQinhuai-Jianye-Gulou-Yuhuatai (XQJGY) region. Results indicated that the transportation infrastructures suffer the largest proportion of flood damage. This study simulates the inundated infrastructure at different return periods, provides a theoretical support for flood risk management.
\end{abstract}

\section{Introduction}

During recent decades, great progress has been made in China's urbanization process. Rapid urbanization has put a lot of pressure on the environment, including water resources and flood risk management, for which more sustainable results are being sought. In terms of disaster risk, unconstrained urbanization can significantly increase both exposure and vulnerability to natural hazards. Generally, urban flooding is caused by extreme runoff in a developed area where drainage is insufficient. [1]. This runoff travels over the surface, pooling in lowlying areas within the catchment until it drains, infiltrates, or evaporates. The infiltration rates in the urban environment tend to be much lower than that of a natural environment due to the modification of hydrologic passageway and the use of impermeable surface [2]. When rapid extreme rainfall events occur, the infrastructure within the city will be severely impacted. This risk is likely to be further exacerbated by changes in the intensity and magnitude of extreme events due to climate change. Based on the above situation, the flood simulation becomes increasingly important and urgent, which suggests decision makers to take flood prevention measures in advance, minimizing the economic losses and casualties.

Flood simulation and modelling can be used to provide forecast information of flood risk at a specific study area. the field of flood simulation has become a central focus of the hydrology in recent years [3]. Topographic data are crucial for flood inundation modelling and it is best to use recent and highly accurate topographic data. According to earlier works, flood simulation methods can be categorized in four categories, numerical simulation [4], remote sensing approaches [5], rainfall data estimation [6] and flood simulation based on geographic information system (GIS) [7]. These methods can solve many important problems. In this paper, flood inundation forecasts are mainly based on the analysis of historical rainfall data, and ArcGIS is used to combine the geographic information data of the research area into the flood simulation. Compared with some hydrological models, the simulation effect of this method is more realistic and can reduce the uncertainty.

With the development of technology, flood disaster has changed from unpredictable to predictable. The damage to existing infrastructure caused by floods is predictable. The overall purpose of this study is to develop an integrated urban flood simulation approach that can accurately simulate the urban flood inundation and assess the damage of infrastructures. Using the case of Xuanwu-Qinhuai-Jianye-Gulou-Yuhuatai (XQJGY) region, we aim to simulate the flood inundation of the central of Nanjing under a rainfall event. Design rainfall at return periods of 50 and 100 years were used to simulate flooding at different levels of severity. Base on the result of flood simulation, we draw the inundation map and extract the flooded infrastructures to assess the impact of floods on various types of infrastructure.

\section{Study area}

This paper choosen Xuanwu-Qinhuai-Jianye-GulouYuhuatai as the study area (Fig.1). The districts of XQJGY are the core region of Nanjing city, with a much higher population density and more frequent human activities. The region is located between latitude $31^{\circ} 14^{\prime}$ $\mathrm{N}-32^{\circ} 37^{\prime} \mathrm{N}$ and longitude $118^{\circ} 22^{\prime} \mathrm{E}-119^{\circ} 14^{\prime} \mathrm{E}$, center of

\footnotetext{
* Corresponding author: upeswp@ujs.edu.cn
} 
Nanjing city located in the north subtropical monsoon climate, with an annual precipitation of 1,200 $\mathrm{mm}$. In recent years, floods have occurred almost every year in Nanjing, leading to the flooding of residential areas with imperfect drainage network construction and paralysis of urban road traffic system. Some of year occurred with large degree and wide coverage. The rapid development of urbanization has brought about a high concentration of population in cities, making cities vulnerable to floods.

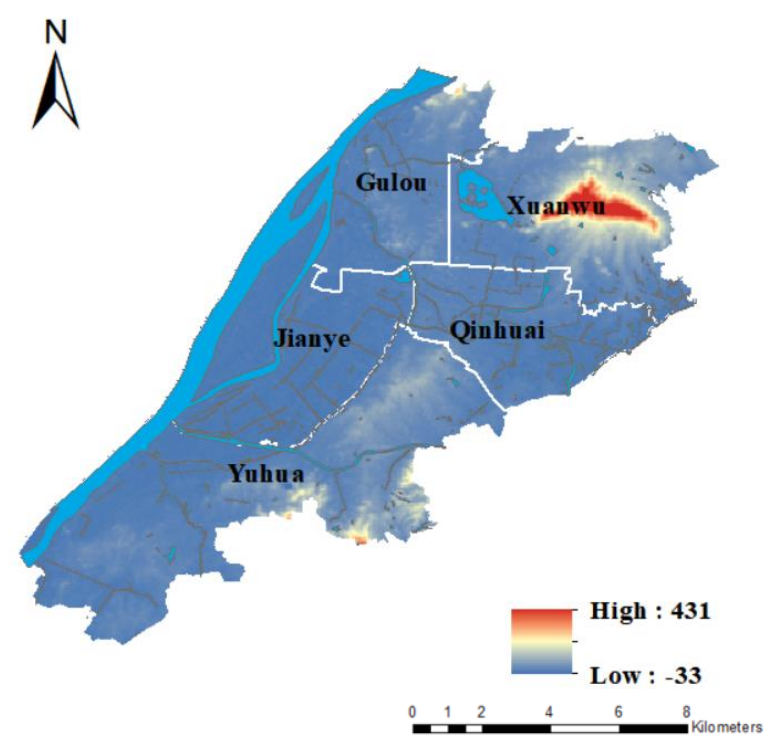

Fig.1 The technical route of flood simulation

\section{Metholody}

First, this study simulated rainstorm event by using the rainstorm intensity equation, with reference to the "China Outdoor Drainage Design Code" (GB500142006) [8]. In equation (1), Where $\mathrm{i}=$ designed rainstorm intensity $(\mathrm{mm} / \mathrm{min}) ; \mathrm{t}=$ rainfall duration $(\mathrm{min}) ; \mathrm{P}=$ return period (year); $\mathrm{n}$ is the attenuation coefficient of rainstorm; $\mathrm{A}_{1}, \mathrm{C}, \mathrm{b}$ are the regional parameters. Equation (2) was the latest rainstorm intensity equation, revised by Nanjing City Administration in 2014.

Second, the Soil Conservation Service Curve Number (SCS-CN), developed by the USDA-Soil Conservation Service, can calculate the effects of different soil types, land use patterns and soil antecedent moisture condition (AMC) on rainfall runoff [9]. SCS$\mathrm{CN}$ model was used to assess the direct runoff for a given rainstorm event. In equation (3)-(6), Where $\mathrm{Q}=$ runoff depth or the effective rainfall $(\mathrm{mm}), \mathrm{P}=$ total rainfall depth ( $\mathrm{mm}), \mathrm{S}=$ potential maximum retention or infiltration $(\mathrm{mm}), \mathrm{I}_{\alpha}$ represents the initial abstraction in $\mathrm{mm}, \alpha$ is the initial abstraction coefficient $(\alpha=0.05$ in this study [10-11], $\mathrm{CN}$ is the curve number ranging from 0 to 100 (dimensionless). $\mathrm{CN}$ represented the runoff potential of the land cover-soil, related to soil antecedent moisture condition (AMC), soil type, and land use and treatment [12]. AMC was classified into three types denoted as AMC I, AMC II, and AMC III: dry (lower limit of moisture or upper limit of $\mathrm{S}$ ), moderate (normal or average soil moisture condition), and wet (upper limit of moisture or lower limit of S). The AMC II was mainly considered to estimate the runoff in this study and the $\mathrm{CN}$ value of AMC II was provided by the SCS-CN manual.

Third, the land use data of Nanjing District in 2018 and runoff depth were used to conduct the modeling of urban flood simulation. Combined with the result of runoff simulation, the flood inundation volume can be calculated as equation (7) and equation (8). The equation (7) is for built-up land, where $\mathrm{V}=$ flood inundation volume $\left(\mathrm{m}^{3}\right), \mathrm{Q}=$ runoff depth $(\mathrm{mm}), \mathrm{S}=$ regional area $\left(\mathrm{km}^{2}\right), \mathrm{C}$ is the urban drainage capacity. For other types of land use equation (8), Where $\mathrm{V}=$ flood inundation volume $\left(\mathrm{m}^{3}\right), \mathrm{Q}=$ runoff depth $(\mathrm{mm}), \mathrm{S}=$ regional area $\left(\mathrm{km}^{2}\right)$.

Finally, with the rainfall runoff calculated in step 2, the 3D Analyst function in ArcGIS is used to calculate the inundation depth in different return period. Based on the DEM of Nanjing, raster calculator function of ArcGIS was used to simulate flood inundation under different regression periods. The flooded infrastructures in the simulation is also extracted by ArcGIS.

The technical route of this study is shown in the Fig. 2

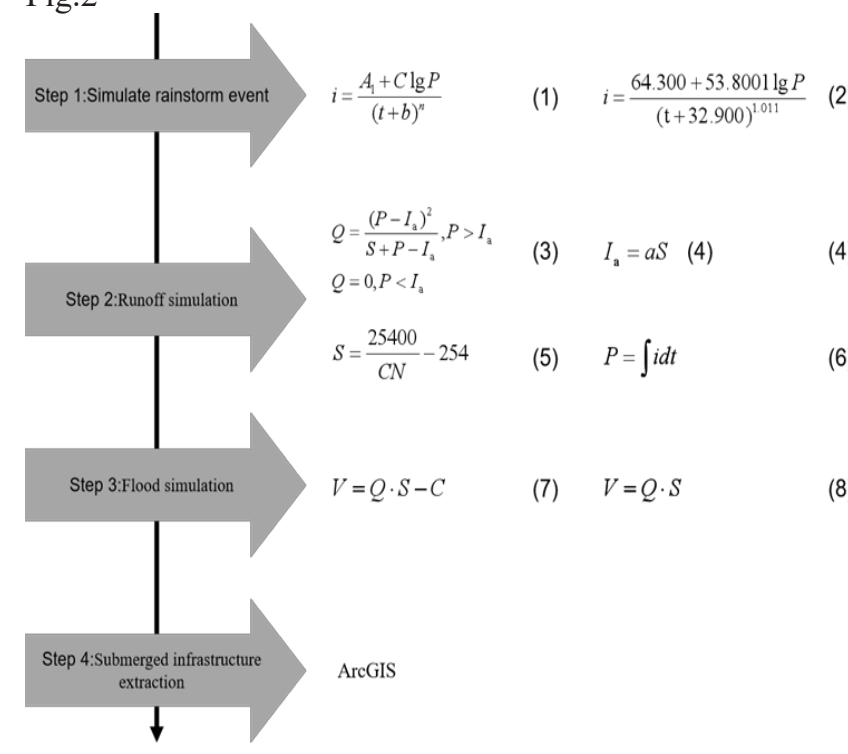

Fig.2 The technical route of flood simulation

\section{Result and discussion}

\subsection{Flood inundation}

Inundation maps show the simulation result of each districts. With the return periods of 50 years and 100 years, the flooded area of Jianye district is both the largest. According to the simulation results, when the return periods of 50 years rainfall occurs, the flooded area of Jianye district is $54.45 \mathrm{~km}^{2}$, accounts for $67.33 \%$ of this district. When the return periods of 50 years rainfall occurs, the flooded area of Jianye district is $59.19 \mathrm{~km}^{2}$, accounts for $73.19 \%$ of this district. Xuanwu district has the smallest submerged area, when the return periods of 100 years rainfall occurs, only $2.8 \mathrm{~km}^{2}$ area 
will be flooded. It's because the flood simulation is closely related to the DEM of study area. The average elevation of Xuanwu district is 12 meters, while the average elevation of Jianye district is 7 meters. The inundation maps of XQJGY with the return periods of 50 years and 100 years are shown in Fig.3 and Fig.4.

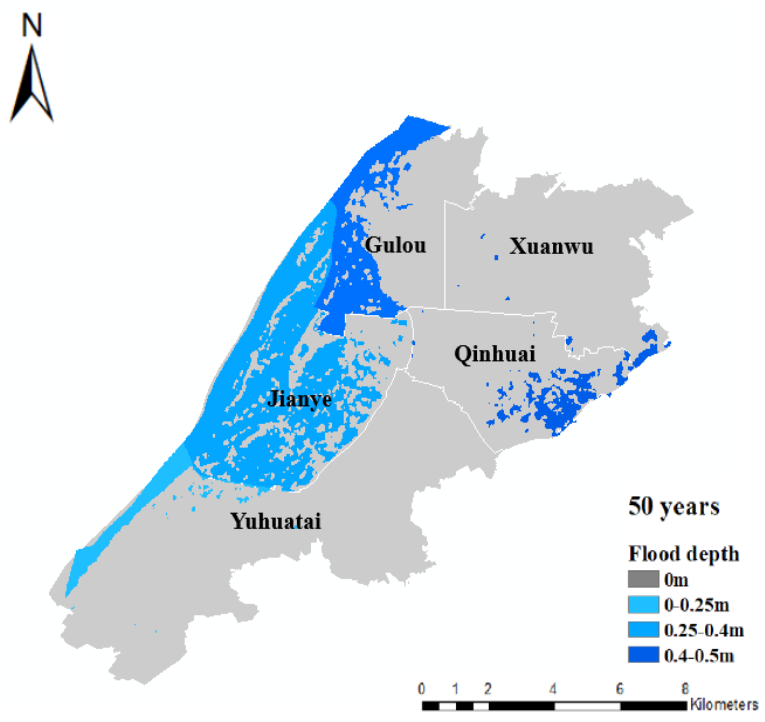

Fig.3 Inundation maps of XQJGY with the return periods of 50 years

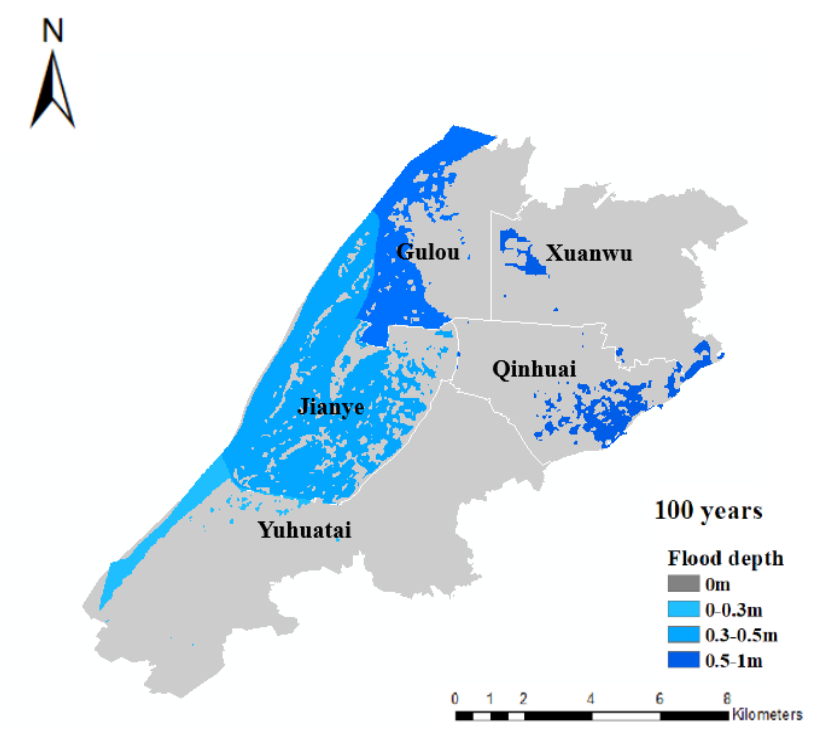

Fig.4 Inundation maps of XQJGY with the return periods of 100 years

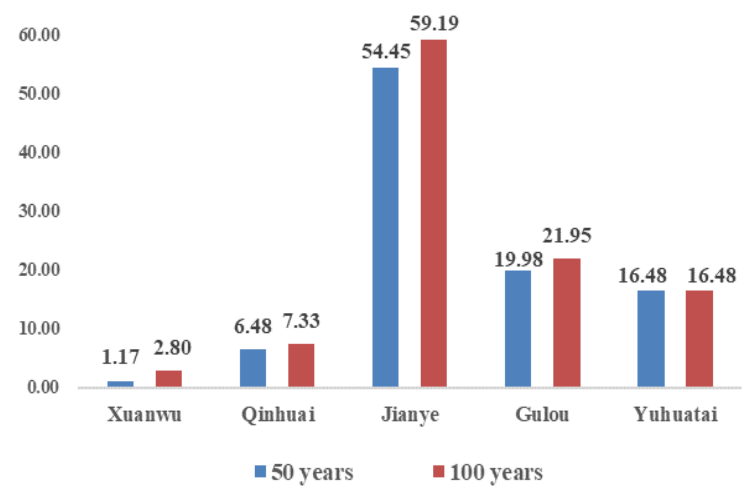

Fig.5 The flooded area of each district with the return periods of 50 years and 100 years

\subsection{Submerged infrastructures}

This paper divided infrastructures into six dimensions: transportation, communication, education, medical and emergency response. The transportation is represented by the length of roads in the study area. The communication is represented by the the amount of communications business offices. The education is represented by the amount of school (kindergarten, primary school, middle school and university) in the study area. The medical is represented by the amount of hospital. The emergency response is represented by the the amount of fire stations. The cultural entertainment is represented by the amount of parks and tourist attractions. According to the simulation results, the damage of infrastructure in Jianye district suffered the greatest effect from the return periods of 50 years and 100 years. The damage of infrastructure in Xuanwu district suffered the least effect from the return periods of 50 years and 100 years. In six types of infrastructure, the transportation infrastructure suffers the largest proportion of flood damage.

The proportion of submerged infrastructure from the return periods of 50 years and 100 years are shown in Table 1 and Table 2.

Table 1. The proportion of submerged infrastructure with the return periods of 50 years

\begin{tabular}{|c|c|c|c|c|c|}
\hline & Xuanwu & Qinhaui & Jianye & Gulou & Yuhuatai \\
\hline Transportation & $11.11 \%$ & $9.53 \%$ & $51.11 \%$ & $29.67 \%$ & $3.62 \%$ \\
\hline Communication & 0 & $23.33 \%$ & $64.00 \%$ & $25.45 \%$ & 0 \\
\hline Education & 0 & $10.00 \%$ & $29.03 \%$ & $38.27 \%$ & $16.67 \%$ \\
\hline
\end{tabular}




\begin{tabular}{|c|c|c|c|c|c|}
\hline Medical & $1.19 \%$ & $2.13 \%$ & $26.67 \%$ & $15.38 \%$ & 0 \\
\hline $\begin{array}{c}\text { Emergency } \\
\text { Response }\end{array}$ & 0 & 0 & 0 & $50 \%$ & 0 \\
\hline $\begin{array}{c}\text { Cultural } \\
\text { Entertainment }\end{array}$ & $31.58 \%$ & $8.33 \%$ & $87.5 \%$ & $18.75 \%$ & $16.67 \%$ \\
\hline
\end{tabular}

Table 2. The proportion of submerged infrastructure with the return periods of 50 years

\begin{tabular}{|c|c|c|c|c|c|}
\hline & Xuanwu & Qinhaui & Jianye & Gulou & Yuhua \\
\hline Transportation & $15.52 \%$ & $10.52 \%$ & $57.59 \%$ & $33.70 \%$ & $3.62 \%$ \\
\hline Communication & $6.12 \%$ & $23.33 \%$ & $76.00 \%$ & $30.90 \%$ & $25.46 \%$ \\
\hline Education & $2.90 \%$ & $12.5 \%$ & $32.26 \%$ & $43.21 \%$ & $16.67 \%$ \\
\hline Medical & $3.57 \%$ & $2.13 \%$ & $12.00 \%$ & $15.39 \%$ & 0 \\
\hline $\begin{array}{c}\text { Emergency } \\
\text { Response }\end{array}$ & 0 & 0 & $33.33 \%$ & $50.00 \%$ & 0 \\
\hline $\begin{array}{c}\text { Cultural } \\
\text { Entertainment }\end{array}$ & 31.58 & $8.33 \%$ & $100 \%$ & $31.25 \%$ & $16.67 \%$ \\
\hline
\end{tabular}

\section{Conclusion}

In this paper, return periods of 50 years and 100 years rainfall events in XQJGY have been simulated. In addition, the damage of various kinds of infrastructure under flood simulation was evaluated. The findings demonstrated that the transportation infrastructures suffer the largest proportion of flood damage. As an important link connecting each subsystem, transportation infrastructures are the arterial system of the city. The occurrence of urban flood is particularly serious to the destruction of transportation infrastructure. With the continuous increase of car ownership, the damage of road infrastructure greatly increases the vulnerability of urban system to flood disaster. Flood control measures can be taken in advance according to the traffic infrastructure submerged by flood in different return periods. According to the simulation results, the areas with lower average elevations are more flooded, the flooded area of Jianye district is the largest.

With the advancement of technology, the flood simulation model will be better improved, and provide theoretical support for flood risk management. In this way, flood simulation becomes the key step of flood risk management which can be better integrated with the wider range of issues that influence urban wellbeing.

\section{Acknowledgments}

This work was supported by the National Natural Science Foundation of China [Grant No. 51908249], the Natural Science Foundation of the Jiangsu Higher Education Institutions of China [Grant No.
19KIB560012], the High-level Scientific Research Foundation for the introduction of talent for Jiangsu University [Grant No. 18JDG038].

\section{References}

1. Weber, A., 2019. What is Urban Flooding? Natural Resources Defense Council (NRDC),

2. S.H. Mahmoud, T.Y. Gan Urbanization and climate change implications in flood risk management: developing an efficient decision support system for flood susceptibility mapping. Science of The Total Environment, 636 (2018), pp. 152-167

3. W. Boughton, O. Droop, Continuous simulation for design flood estimation-a re view, Environ. Model. Softw 18 (4) (2003) 309-318

4. O. Mark, S. Weesakul, C. Apirumanekul, S.B. Aroonnet, S. Djordjevic, Potential and limitations of 1D modelling of urban flooding, J. Hydrol. (2004) 284-299.

5. F. Franci, G. Bitelli, E. Mandanici, D. Hadjimitsis, A. Agapiou, Satellite remote sensing and GIS-based multi-criteria analysis for flood hazard mapping, Nat.Hazards 83 (2016) 31-51

6. A.L. Kay, N.S. Reynard, R.G. Jones, RCM rainfall for UK flood frequency estimation.I. Method and validation, J. Hydrol. 318 Elsevier, 2006, pp. 1511622006

7. K. Uddin, D.R. Gurung, Giriraj Amarnath, B. Shrestha, Application of remote sen sing and GIS for flood hazard management: a case study from 
Sindh Province, Pakistan, Am. J. Geogr. Inf. Syst. 2 (1) (2013) 1-5

8. Shi, Zhi Hua, Li Ding Chen, Nu Fang Fang, De Fu Qin, and Chong Fa Cai. 2009. "Research on the SCS-CN Initial Abstraction Ratio Using RainfallRunoff Event Analysis in the Three Gorges Area, China." Catena 77 (1): 1-7.

9. Wang, Chen, Jingming Hou, David Miller, Iain Brown, and Yang Jiang. 2019. "Flood Risk Management in Sponge Cities: The Role of Integrated Simulation and 3D Visualization." International Journal of Disaster Risk Reduction 39 (December 2018): 101139.

10. Baltas, E. A., N. A. Dervos, and M. A. Mimikou. 2007. "Technical Note: Determination of the SCS Initial Abstraction Ratio in an Experimental Watershed in Greece." Hydrology and Earth System Sciences 11 (6): 1825-29.

11. Lim, Kyoung Jae, Bernard A. Engel, Suresh Muthukrishnan, and Jon Harbor. 2006. "Effects of Initial Abstraction and Urbanization on Estimated Runoff Using CN Technology." Journal of the American Water Resources Association 42 (3): 62943.

12. Xiao, Bo, Qing Hai Wang, Jun Fan, Feng Peng Han, and Quan Hou Dai. 2011. "Application of the SCS$\mathrm{CN}$ Model to Runoff Estimation in a Small Watershed with High Spatial Heterogeneity." Pedosphere 21 (6): 738-49. 